\title{
Eficiência do sistema de nove covas na seleção de progênies de feijoeiro tipo carioca para arquitetura ereta
}

\author{
Flávia Ferreira Mendes ${ }^{(1)}$, Magno Antônio Patto Ramalho(1) e Ângela de Fátima Barbosa Abreu(2)
} (1)Universidade Federal de Lavras, Departamento de Biologia, Caixa Postal 37, CEP 37200-000 Lavras, MG. E-mail: flvmendes2001@yahoo.com.br,
magnoapr@ufla.br (2)Embrapa Arroz e Feijão, Caixa Postal 37, CEP 37200-000 Lavras, MG. E-mail: afbabreu@ufla.br

Resumo - O objetivo deste trabalho foi verificar a eficiência do sistema de nove covas na avaliação de progênies de feijoeiro (Phaseolus vulgaris) tipo carioca quanto à arquitetura da planta. Foram avaliadas 97 progênies nas gerações $\mathrm{F}_{2: 3}$ e $\mathrm{F}_{2: 4}$, em delineamento de blocos ao acaso, com 20 repetições e nove plantas por parcela, em que a planta central foi avaliada, e as oito vizinhas foram consideradas conjuntamente como controle. Avaliaram-se os caracteres: produção de grãos por planta, porte e acamamento. O índice de seleção conjunta, para as três características $\left(Z_{\mathrm{ij}}\right)$, foi obtido pelo somatório dos valores padronizados por parcela. Os dados foram submetidos à análise de variância e, a partir das esperanças dos quadrados médios, foram estimados os componentes de variância. É possível identificar plantas mais eretas em populações segregantes do feijoeiro, utilizando-se o sistema de nove covas. Este sistema possibilita a obtenção de elevadas estimativas de acurácia experimental e herdabilidade.

Termos para indexação: Phaseolus vulgaris, acamamento, herdabilidade, índice de seleção, precisão experimental.

\section{Nine-hole system efficiency in selection of carioca-type common bean progenies for erect architecture}

\begin{abstract}
The objective of this work was to verify the nine-hole system efficiency in the evaluation of common bean (Phaseolus vulgaris) carioca-type progenies for plant architecture. Ninety-seven progenies were evaluated in the $\mathrm{F}_{2: 3}$ and $\mathrm{F}_{2: 4}$ generations in an randomized block design, with 20 replicates, and nine plants per plot, in which the central plant was evaluated, and the eight neighbor ones were considered together as the control. The evaluated traits were: grain yield per plant, architecture and lodging. The joint selection index $\left(Z_{\mathrm{ij}}\right)$ for the three characters was obtained through the sum of the standardized values per plot. Data were submitted to the analysis of variance, and from the mean square expected values, the components of variance were estimated. It is possible to identify more upright plants using the nine-hole system, in segregating common bean populations. This system allows for high estimates of experimental accuracy and heritability.
\end{abstract}

Index terms: Phaseolus vulgaris, lodging, heritability, selection index, experimental precision.

\section{Introdução}

A utilização de plantas com porte mais ereto, menor acamamento e alta produtividade tem sido objetivo da maioria dos programas de melhoramento do feijoeiro (Phaseolus vulgaris L.). O cultivo de plantas mais eretas, com menor suscetibilidade ao acamamento, propicia vantagens como a maior facilidade na realização dos tratos culturais e da colheita mecânica.

Aseleçãodeplantas eretas, commenoracamamento, não tem sido fácil em razão do grande número de genes envolvidos e, sobretudo, pelo efeito do ambiente (Menezes Júnior et al., 2008). Além disso, em condições de umidade e temperaturas elevadas e solo rico em matéria orgânica, há tendência de as plantas se tornarem decumbentes, mesmo as com hábito de crescimento do tipo II, consideradas mais eretas. Outro problema, relacionado às avaliações realizadas em condição de alta temperatura e umidade, é o maior desenvolvimento vegetativo das plantas, pois, aquelas que não são eretas caem sobre as vizinhas e formam um emaranhado de plantas que dificulta, inclusive, a circulação no campo e a avaliação do desempenho individual das progênies. Por essas razões, mesmo em um programa que vise à seleção quanto à arquitetura das plantas, algumas linhagens consideradas eretas, a depender da condição de cultivo, podem vir a ser descartadas pela impossibilidade da avaliação precisa desse caráter nas populações segregantes. 
Para facilitar a avaliação da arquitetura da planta de feijoeiro, Menezes Júnior et al. (2008) sugeriram aumentar o tamanho da parcela. Contudo, quando o número de progênies é grande, a área experimental pode ser limitante. Além disso, em gerações precoces, o número de sementes é pequeno e, portanto, essa estratégia seria aplicável apenas em gerações mais avançadas.

No sistema tradicional de seleção, com condução das populações pelo método de "bulk", as plantas são semeadas em linha na parcela, e a segregação dentro das progênies praticamente não é considerada. A avaliação do porte é realizada com base no desempenho médio da progênie. Se alguma planta se destacar com porte ereto dentro de uma progênie que, em média, não tem porte ereto, seu mérito fica prejudicado e ela é descartada. Para contornar esse problema, uma alternativa seria avaliar as progênies utilizando-se parcela de uma planta. Assim, Fasoulas (1973) propôs um método denominado "honeycomb". Esse tipo de arranjo visa avaliar as plantas sob as mesmas condições de competição e possibilita a análise espacial dos dados (Bos, 1983; Kempton \& Gleeson, 1997; Fasoula \& Fasoula, 2000). Entretanto, o emprego de apenas uma planta por parcela não resolve inteiramente o problema, pois, se os vizinhos forem decumbentes, eles podem mascarar a expressão da planta ereta. A opção seria, então, a utilização de um sistema em que as plantas vizinhas sejam sempre de mesmo genótipo. Esse é o caso do sistema de nove covas.

$\mathrm{Na}$ seleção de plantas de feijoeiro com melhor arquitetura, outras características são igualmente importantes e devem ser levadas em consideração, como acamamento e produtividade de grãos. A seleção simultânea quanto a caracteres múltiplos é normalmente realizada por meio de índices de seleção (Missio et al., 2004; Vieira et al., 2005). Na literatura, há várias opções de índices (Cruz \& Carneiro, 2006), um dos quais ainda pouco explorado na cultura do feijoeiro é a obtenção do índice por meio do somatório das variáveis padronizadas $\left(\Sigma Z_{i j}\right)$. Mendes et al. (2009) propuseram a utilização de um índice para seleção de plantas de feijoeiro com uso de variáveis padronizadas, que considera as características arquitetura, acamamento e produtividade de grãos simultaneamente.

O objetivo deste trabalho foi verificar a eficiência do sistema de nove covas na avaliação de progênies do feijoeiro tipo carioca, quanto à arquitetura da planta.

\section{Material e Métodos}

O trabalho foi realizado na área experimental do Departamento de Biologia, da Universidade Federal de Lavras (Ufla). As progênies utilizadas na avaliação provieram das populações CVIII8511 x RP26 e MAII22 x RP26. O genitor RP26, comum às duas populações, apresenta porte ereto e grãos tipo carioca; porém, com algumas restrições de comercialização, especialmente quanto ao tamanho de grãos. Os genitores MAII22 e CVIII8511 pertencem ao programa de melhoramento genético da Ufla, apresentam grãos do tipo carioca e boa produtividade de grãos; contudo, não possuem porte ereto.

Foram utilizadas 97 progênies $\mathrm{F}_{2: 3}, 51$ provenientes da população CVIII8511 x RP26 e 46 da população MAII22 x RP26. As progênies $F_{2: 3}$, com os três genitores (100 tratamentos), foram avaliados em experimento com semeadura em fevereiro de 2008 (safra de seca). Em julho de 2008 (safra de inverno), as mesmas progênies foram avaliadas na geração $\mathrm{F}_{2: 4}$. Em ambos os experimentos, utilizou-se $\mathrm{o}$ delineamento de blocos ao acaso, com 20 repetições. As parcelas foram constituídas por nove plantas, em arranjo semelhante ao adotado por Silva et al. (2007), em que cada progênie, disposta na cova central, era rodeada por oito plantas de uma mesma testemunha. No presente trabalho, utilizou-se a cultivar Supremo. Essa cultivar, de feijão-preto, foi escolhida por ter porte bem ereto e caules e flores de cor violeta, de modo a possibilitar a fácil diferenciação das plantas sob teste, que apresentavam caule verde, flores brancas e grãos de cor creme com estrias marrons. Adicionalmente, houve a vantagem de se poder avaliar o porte da planta sob teste, com um genótipo de porte bem ereto como referência.

A distância entre covas foi de $20 \mathrm{~cm}$. A marcação das covas foi feita com régua, e foram utilizadas três sementes por cova. Quinze dias após a emergência, foi realizado o desbaste, tendo-se deixado uma planta por cova.

Foram empregados os tratos culturais normais para a cultura do feijão na região, acrescidos da irrigação por aspersão, sempre que necessária. Os caracteres avaliados foram: porte, por meio de escala de notas de 1 a 9, conforme Mendes et al. (2009), em que a nota 9 refere-se à planta do tipo II, ereta, com uma haste e alta inserção das primeiras vagens, e a nota 1 à planta do tipo III, com entrenós longos e completamente 
prostrada; acamamento, também avaliado por meio de escala de notas, em que a nota 9 refere-se à planta não acamada e a nota 1 à planta completamente acamada; e produção de grãos (grama por parcela), medida pela pesagem dos grãos (a 13\% de umidade) das plantas colhidas individualmente.

$\mathrm{O}$ índice $\mathrm{Z}$ foi calculado para possibilitar a avaliação das três características simultaneamente. Para tanto, obteve-se o somatório dos valores padronizados (Z) de cada caráter, conforme Mendes et al. (2009). Para a padronização, utilizou-se a expressão $\mathrm{Z}_{\mathrm{ij}}=\left(\mathrm{y}_{\mathrm{ij}}-\overline{\mathrm{y}}_{\mathrm{j}}\right) / \mathrm{s}_{\mathrm{j}}$ em que: $\mathrm{Z}_{\mathrm{ij}}$ é o valor da variável padronizada do tratamento $\mathrm{i}(\mathrm{i}=1,2, \ldots, 100)$, na repetição $\mathrm{j}(\mathrm{j}=1,2, \ldots, 20) ; \mathrm{y}_{\mathrm{ij}}$ é a observação da variável do tratamento i na repetição $\mathrm{j}$; $\overline{\mathrm{y}}_{\mathrm{j}}$ é a média geral da variável na repetição j; e $\mathrm{s}_{\mathrm{j}}$ é o desvio-padrão fenotípico da variável na repetição j. Como a variável $Z_{i j}$ pode ser negativa ou positiva, utilizou-se um fator de correção com valor três, que foi somado aos valores padronizados de modo a não se ter valores negativos. Nesse caso, a média geral, em vez de zero, passa a ser três. Após a padronização das variáveis, foi obtido o somatório $Z_{\mathrm{ij}}$ por parcela, que corresponde ao somatório das três variáveis padronizadas.

Procedeu-se às análises de variância para todas as características. Posteriormente, foram realizadas as análises de variância conjuntas, com procedimento semelhante ao apresentado por Ramalho et al. (2005), tendo-se considerado como fixas as fontes de variação média e geração e, como aleatórias, as demais fontes de variação. Para realizar as análises de variância, foi utilizado o programa estatístico MSTAT-C (1991).

A partir das esperanças matemáticas dos quadrados médios das análises conjuntas, foram obtidas as estimativas de variâncias genéticas e fenotípicas entre as médias das progênies e as herdabilidades $\left(\mathrm{h}_{\mathrm{a}}^{2}\right)$ no sentido amplo, para a seleção da média das progênies. A variância genética livre da interação foi obtida pela estimativa da covariância entre a média das progênies, nas duas gerações.

Estimou-se a herdabilidade realizada $\left(\mathrm{h}_{\mathrm{r}}^{2}\right)$, tendo-se considerado o ganho realizado na geração $\mathrm{F}_{2: 4}$, pela seleção de $10 \%$ das melhores progênies em $\mathrm{F}_{2: 3}$, de acordo com a expressão $\mathrm{h}_{\mathrm{r}}^{2}=\left(\mathrm{GS}_{\mathrm{F} 2: 4} / \mathrm{m}_{\mathrm{j}}\right) /\left(\mathrm{ds}_{\mathrm{F} 2: 3} / \mathrm{m}_{\mathrm{i}}\right)$, em que: $\mathrm{ds}_{\mathrm{F} 2: 3}$ é o diferencial de seleção com a seleção de $10 \%$ das melhores progênies $\mathrm{F}_{2: 3} ; \mathrm{GS}_{\mathrm{F} 2: 4}$ é o ganho de seleção observado na geração $F_{2: 4}$, pela seleção realizada entre $10 \%$ das melhores progênies em $\mathrm{F}_{2: 3}$; $\mathrm{m}_{\mathrm{i}}$ é a média das progênies na geração $\mathrm{F}_{2: 3} ; \mathrm{m}_{\mathrm{j}}$ é a média das progênies na geração $F_{2: 4}$. $O$ ganho com a seleção (GS) também foi estimado com a seleção de $10 \%$ das melhores progênies na média das duas gerações.

A precisão experimental foi avaliada por meio da avaliação dos coeficientes de variação experimental (CV) e da acurácia seletiva (AS) (Resende \& Duarte, 2007), calculada por meio das expressões: $\mathrm{AS}=[1-(1 / \mathrm{Fc})]^{0,5}$ para $\mathrm{Fc} \geq 1$; e $\mathrm{AS}=0$, para $\mathrm{Fc}<1$, em que $\mathrm{Fc}$ é o valor do teste $\mathrm{F}$ para genótipo.

\section{Resultados e Discussão}

No presente trabalho, a estimativa dos CV para a produtividade foi de aproximadamente 34\% (Tabela 1). Portanto, o experimento pode ser considerado de baixa precisão quanto a esse parâmetro. Contudo, o emprego do CV como indicador da precisão experimental tem sido questionado, pois sua estimativa depende da magnitude da média e do número de repetições utilizadas (Cargnelutti Filho \& Storck, 2007; Resende \& Duarte, 2007). Alternativas têm sido propostas para avaliar a precisão experimental. Resende \& Duarte (2007) propuseram o emprego da estimativa da acurácia seletiva, que se refere à correlação entre o valor genotípico verdadeiro do tratamento genético e aquele estimado ou predito a partir de informações dos experimentos $\left(\hat{\mathrm{r}}_{\mathrm{g}^{\prime} \mathrm{g}}\right)$. Em última análise, ela reflete $\mathrm{o}$ que os melhoristas desejam, isto é, que o fenótipo seja um bom preditor do genótipo. No presente trabalho, as estimativas de acurácia, quanto à produtividade de grãos e nota de porte, podem ser consideradas como alta e muito alta, respectivamente, segundo a classificação de Resende (2007). Uma das razões para a alta precisão e, consequentemente, alta acurácia observada é a possibilidade de se utilizar um grande número de repetições com o emprego da metodologia de nove covas.

Foi constatada diferença significativa entre as progênies, nas duas populações, para todas as características (Tabela 1), condição imprescindível para trabalhos desta natureza. A amplitude de variação da produção de grãos da população CVIII8511 x RP26 foi de $8,05 \mathrm{~g}$ por planta, o que corresponde a $25,8 \%$ da média. Para a população MAII22 x RP26, a amplitude foi ainda maior, de 14,2 g por planta, ou seja, 39,9\% 
da média. Com relação à nota de porte, observou-se maior amplitude de variação na população CVIII8511 x RP26, que foi de 2,57 (41,4\% da média), enquanto na população MAII22 x RP26 foi de 2,08 (38,4\% da média). Quando os três caracteres foram considerados simultaneamente, a amplitude foi maior na população CVIII8511 x RP26 (28,9\% da média das progênies), ao passo que na população MAII22 x RP26 foi de $12,9 \%$ da média.
A existência de variabilidade genética entre as progênies, quantos aos caracteres avaliados, pode ser comprovada também pelas estimativas dos parâmetros genéticos (Tabela 2). As estimativas das variâncias genéticas entre as progênies $\left(\hat{\sigma}_{\mathrm{p}}^{2}\right)$ foram todas diferentes de zero. Em nenhuma das situações se obteve estimativa do limite inferior negativa $(\mathrm{p} \leq 0,05)$. $\mathrm{Na}$ maioria das situações, as estimativas de $\hat{\sigma}_{\mathrm{p}}^{2}$ foram semelhantes nas duas populações, para todas as características,

Tabela 1. Resumo da análise de variância conjunta, para as características produtividade de grãos, nota de porte, nota de acamamento e índice $\mathrm{Z}$ de progênies de feijão-comum, avaliadas nas gerações $\mathrm{F}_{2: 3}$ e $\mathrm{F}_{2: 4}$.

\begin{tabular}{|c|c|c|c|c|c|c|c|c|}
\hline \multirow[t]{2}{*}{ Fonte de variação } & \multicolumn{2}{|c|}{ Produtividade } & \multicolumn{2}{|c|}{ Porte } & \multicolumn{2}{|c|}{ Acamamento } & \multicolumn{2}{|c|}{ Índice $Z$} \\
\hline & GL & QM & GL & QM & GL & QM & GL & QM \\
\hline Bloco/geração & 38 & $1.080,22$ & 38 & 7,59 & 38 & 25,15 & 38 & 0,09 \\
\hline Geração (S) & 1 & $88.669,2 * *$ & 1 & $240,16 * *$ & 1 & $30,37 * *$ & 1 & $0,27^{\mathrm{ns}}$ \\
\hline Tratamentos $(\mathrm{T})$ & 99 & $676,41 * *$ & 99 & $21,36^{* *}$ & 99 & $11,62 * *$ & 99 & $15,50^{* *}$ \\
\hline Progênies (P) & 96 & $671,92 * *$ & 96 & $19,46^{* *}$ & 96 & $11,63 * *$ & 96 & $14,34 * *$ \\
\hline Entre $\mathrm{P}_{1}$ & 50 & $366,02 * *$ & 50 & $14,74 * *$ & 50 & $12,28^{* *}$ & 50 & $14,26 * *$ \\
\hline Entre $\mathrm{P}_{2}$ & 45 & $583,16 * *$ & 45 & $11,71^{* *}$ & 45 & $7,36 * *$ & 45 & $11,45^{* *}$ \\
\hline $\mathrm{P}_{1}$ vs $\mathrm{P}_{2}$ & 1 & $19.961,8 * *$ & 1 & $604,33 * *$ & 1 & $171,45^{* *}$ & 1 & $148,5^{* *}$ \\
\hline Genitor (G) & 2 & $867,72 * *$ & 2 & $111,10^{* *}$ & 2 & $15,01 * *$ & 2 & $69,35^{* *}$ \\
\hline G vs S & 1 & $724,53 *$ & 1 & $24,72 * *$ & 1 & $3,96^{\mathrm{ns}}$ & 1 & $18,57^{* *}$ \\
\hline $\mathrm{T} \times \mathrm{S}$ & 99 & $221,36^{*}$ & 99 & $2,43 *$ & 99 & $4,01 *$ & 99 & $3,80^{*}$ \\
\hline $\mathrm{P} \times \mathrm{S}$ & 96 & $225,88^{*}$ & 96 & $2,49^{*}$ & 96 & $4,11^{*}$ & 96 & $3,87^{*}$ \\
\hline Entre $\mathrm{P}_{1} \times \mathrm{S}$ & 50 & $175,24^{\mathrm{ns}}$ & 50 & $2,41 *$ & 50 & $3,61 *$ & 50 & $4,13 * *$ \\
\hline Entre $\mathrm{P}_{2} \times \mathrm{S}$ & 45 & $286,87^{*}$ & 45 & $2,62 *$ & 45 & $4,35^{* *}$ & 45 & $3,29^{\mathrm{ns}}$ \\
\hline $\mathrm{P}_{1}$ vs $\mathrm{P}_{2} \times \mathrm{S}$ & 1 & $13,33^{\text {ns }}$ & 1 & $0,64^{\mathrm{ns}}$ & 1 & $18,31 * *$ & 1 & $16,97^{* *}$ \\
\hline $\mathrm{G} \times \mathrm{S}$ & 2 & $71,17^{\text {ns }}$ & 2 & $0,57^{\mathrm{ns}}$ & 2 & $1,12^{\mathrm{ns}}$ & 2 & $2,30^{\text {ns }}$ \\
\hline$(P \vee v G) \times S$ & 1 & $87,82^{\text {ns }}$ & 1 & $0,39^{\text {ns }}$ & 1 & $0,19^{\text {ns }}$ & 1 & $0,08^{\text {ns }}$ \\
\hline Resíduo & 3.524 & 141,34 & 3.534 & 1,81 & 3.535 & 2,59 & 3.488 & 2,75 \\
\hline $\mathrm{CV}(\%)$ & \multicolumn{2}{|r|}{34,69} & \multicolumn{2}{|c|}{22,43} & \multicolumn{2}{|c|}{21,59} & \multicolumn{2}{|c|}{18,43} \\
\hline Acurácia (\%) & \multicolumn{2}{|r|}{81,71} & \multicolumn{2}{|c|}{93,53} & \multicolumn{2}{|c|}{80,74} & \multicolumn{2}{|c|}{86,43} \\
\hline Média de $\mathrm{P}_{1}$ & \multicolumn{2}{|r|}{31,03} & \multicolumn{2}{|c|}{6,21} & \multicolumn{2}{|c|}{7,42} & \multicolumn{2}{|c|}{9,21} \\
\hline Média de $\mathrm{P}_{2}$ & \multicolumn{2}{|r|}{35,58} & \multicolumn{2}{|c|}{5,42} & \multicolumn{2}{|c|}{7,00} & \multicolumn{2}{|c|}{8,81} \\
\hline Média dos genitores & \multicolumn{2}{|r|}{30,69} & \multicolumn{2}{|c|}{5,37} & \multicolumn{2}{|c|}{7,41} & \multicolumn{2}{|c|}{8,62} \\
\hline Média geral & \multicolumn{2}{|r|}{33,11} & \multicolumn{2}{|c|}{5,82} & \multicolumn{2}{|c|}{7,23} & \multicolumn{2}{|c|}{9,00} \\
\hline
\end{tabular}

${ }^{n n}$ Não significativo. * e **Significativo a 5 e $1 \%$ de probabilidade, pelo teste $\mathrm{F}$, respectivamente. $\mathrm{P}_{1}$, progênies da população CVIII8511 x RP26; $\mathrm{P}_{2}$, progênies da população MAII22 x RP26.

Tabela 2. Estimativas dos componentes de variância genética da análise conjunta, para as características produtividade de grãos, nota de porte, nota de acamamento e índice Z, de progênies de feijão-comum ${ }^{(1)}$.

\begin{tabular}{lcccc}
\hline Componente & Produtividade & Porte & Acamamento & Índice $Z$ \\
\hline$\hat{\sigma}_{\mathrm{p}}^{2}$ & $11,2(8,56-15,1)$ & $0,418(0,32-0,57)$ & $0,187(0,15-0,26)$ & $0,263(0,20-0,35)$ \\
$\hat{\sigma}_{\mathrm{p} 1}^{2}$ & $4,77(3,34-7,37)$ & $0,306(0,22-0,48)$ & $0,222(0,15-0,34)$ & $0,246(0,18-0,39)$ \\
$\hat{\sigma}_{\mathrm{p} 2}^{2}$ & $7,41(5,10-11,80)$ & $0,232(0,16-0,37)$ & $0,078(0,06-0,13)$ & $0,199(0,14-0,32)$ \\
\hline
\end{tabular}

${ }^{(1)}$ Valores entre parênteses referem-se aos limites inferior e superior; $\hat{\sigma}_{\mathrm{p}}^{2}$, variância genética entre progênies; $\hat{\sigma}_{\mathrm{pl}}^{2}$, variância genética entre progênies da população CVIII8511 x RP26; $\hat{\sigma}_{\mathrm{p} 2}^{2}$, variância genética entre progênies da população MAII22 x RP26. 
pois, observou-se ocorrência de sobreposição nos intervalos de confiança.

Todas as estimativas de herdabilidade foram superiores a $40 \%$, e os intervalos de confiança apresentaram limites inferiores positivos e, portanto, diferentes de zero (Tabela 3). As menores estimativas foram observadas quanto à produtividade de grãos. Há diversos relatos, na literatura, de estimativas de herdabilidade quanto à produtividade de grãos. As estimativas encontradas no presente trabalho estão dentro do intervalo de variação relatado no levantamento realizado por Moreto et al. (2007), em populações de feijoeiro. Quanto ao índice de seleção, as estimativas de herdabilidade também foram altas (71\%) para ambas as populações.

Constatou-se, neste trabalho, que os quadrados médios da interação progênies x gerações foram significativos, para todas as características avaliadas (Tabela 1). Infere-se, portanto, que as progênies tiveram comportamento não coincidente nas duas gerações. Entretanto, independentemente da população, a soma de quadrados da interação progênies $x$ gerações correspondeu a apenas $32,73 \%$ da soma de quadrados de tratamentos, para a produtividade de grãos, $11,38 \%$, para nota de porte, e $34,51 \%$, para nota de acamamento.

Para verificar o efeito da interação no ganho com a seleção, foi simulada a seleção de $10 \%$ das melhores progênies na $F_{2: 3}$ e a resposta à seleção na $\mathrm{F}_{2: 4}$. A partir desses dados, foi possível calcular a herdabilidade realizada, tendose considerado todas as progênies, de acordo com Ramalho et al. (1993). As herdabilidades realizadas foram inferiores às herdabilidades obtidas na geração $F_{2: 3}$ (Tabela 4). Contudo, a proporção da herdabilidade realizada em relação à herdabilidade estimada na geração $F_{2: 3}$ $\left(\mathrm{h}_{\mathrm{r}}^{2} / \mathrm{h}^{2}\right)$ foi sempre superior a $68 \%$, o que indica baixa expressividade da interação.

O ganho esperado com a seleção foi semelhante nas duas populações, ao se considerar a seleção de $10 \%$ das melhores progênies, quanto às três características avaliadas. Os maiores ganhos foram observados quanto ao porte da planta. Para o índice $Z$, foram obtidas estimativas superiores a 3,51\% (Tabela 3).
Tabela 3. Estimativas médias das gerações $\mathrm{F}_{2: 3}$ e $\mathrm{F}_{2: 4}$, quanto à herdabilidade $\left(\mathrm{h}^{2}, \%\right)$ e o ganho com a seleção (GS, \%), tendo-se considerado a intensidade de seleção de $10 \%$ das melhores progênies, para as características produtividade de grãos, nota de porte, nota de acamamento e índice Z, em feijão-comum $^{(1)}$.

\begin{tabular}{lcccc}
\hline Herdabilidade Produtividade & Porte & Acamamento & Índice Z \\
\hline $\mathrm{h}_{\mathrm{p}}^{2}$ & $66,3(55-75)$ & $86,7(83-90)$ & $65,1(53-74)$ & $72,8(64-80)$ \\
$\mathrm{h}_{\mathrm{p} 1}^{2}$ & $52,4(18-54)$ & $83,9(78-87)$ & $71,2(56-75)$ & $70,7(64-80)$ \\
$\mathrm{h}_{\mathrm{p} 2}^{2}$ & $51,3(49-71)$ & $77,8(72-84)$ & $41,2(26-58)$ & $71,3(55-75)$ \\
$\mathrm{GS}_{\mathrm{p} 1}$ & 8,93 & 11,36 & 8,32 & 3,94 \\
$\mathrm{GS}_{\mathrm{p} 2}$ & 9,50 & 13,09 & 3,81 & 3,51 \\
\hline
\end{tabular}

${ }^{(1)}$ Valores entre parênteses referem-se aos limites inferior e superior; $h_{\mathrm{p}}^{2}$, herdabilidade de progênies; $\mathrm{h}_{\mathrm{p}}^{2}$, herdabilidade de progênies da população CVIII8511 x RP26; $\mathrm{h}_{\mathrm{p} 2}^{2}$, herdabilidade de progênies da população MAII22 x RP26.

Tabela 4. Estimativas de herdabilidade $\left(h^{2}, \%\right)$ entre progênies $\mathrm{F}_{2: 3}$, herdabilidade realizada $\left(\mathrm{h}_{\mathrm{r}}^{2}\right)$ e proporção da herdabilidade realizada, em relação à herdabilidade estimada, considerando-se a seleção das $10 \%$ melhores progênies em $\mathrm{F}_{2: 3}$ e resposta em $\mathrm{F}_{2: 4}$, em feijão-comum.

\begin{tabular}{lcccc}
\hline Herdabilidade & Produtividade & Porte & Acamamento & Índice $\mathrm{Z}$ \\
\hline $\mathrm{h}^{2}$ & 65,4 & 81,6 & 60,4 & 65,7 \\
$\mathrm{~h}_{\mathrm{r}}^{2}$ & 44,3 & 76,2 & 51,2 & 54,7 \\
$\left(\mathrm{~h}_{\mathrm{r}}^{2} / \mathrm{h}^{2}\right) \times 100$ & 67,7 & 93,4 & 84,7 & 83,3 \\
\hline
\end{tabular}

\section{Conclusões}

1. É possível identificar plantas produtivas, de arquitetura mais ereta e menor acamamento, em populações segregantes de feijoeiro, pelo sistema de nove covas.

2. O sistema nove covas possibilita obter altas estimativas de acurácia experimental e de herdabilidade para a seleção da média das progênies.

\section{Agradecimentos}

À Fundação de Amparo à Pesquisa do Estado de Minas Gerais, pelo apoio financeiro; ao Conselho Nacional de Desenvolvimento Científico e Tecnológico, por concessão de bolsa.

\section{Referências}

BOS, I. Some remarks on honeycomb selection. Euphytica, v.32, p.329-334, 1983.

CARGNELUTTI FILHO, A.; STORCK, L. Estatísticas de avaliação da precisão experimental em ensaios de cultivares de milho. Pesquisa Agropecuária Brasileira, v.42, p.17-24, 2007. 
CRUZ, C.D.; CARNEIRO, P.C.S. Modelos biométricos aplicados ao melhoramento genético. Viçosa: UFV, 2006. 585p.

FASOULA, V.A.; FASOULA, D.A. Honeycomb breeding: principles and applications. Plant Breeding Reviews, v.18, p.177-250, 2000.

FASOULAS, A. A new approach to breeding superior yielding varieties. Thessaloniki: Aristotelian University of Thessaloniki, 1973. 42p.

KEMPTON, R.A.; GLEESON, R.A. Unreplicated trials. In: KEMPTON, R.A.; FOX, P.N. (Ed.). Statistical methods for plant variety evaluation. London: Chapman and Hall, 1997. p.86-100.

MENDES, F.F.; RAMALHO, M.A.P.; ABREU, A. de F.B. Índice de seleção para escolha de populações segregantes de feijoeiro-comum. Pesquisa Agropecuária Brasileira, v.44, p.1312-1318, 2009.

MENEZES JÚNIOR, J.A.N. de; RAMALHO, M.A.P.; ABREU, Â. de F.B. Seleção recorrente para três caracteres do feijão. Bragantia, v.67, p.833-838, 2008.

MISSIO, R.F.; CAMBUIM, J.; MORAES, M.L.T. de; PAULA, R.C. de. Seleção simultânea de caracteres em progênies de Pinus caribaea Morelet var. bahamensis. Scientia Forestalis, n.66, p.161-168, 2004.

MORETO, A.L.; RAMALHO, M.A.P.; NUNES, J.A.R.; ABREU, A. de F.B. Estimação dos componentes da variância fenotípica em feijoeiro utilizando o método genealógico. Ciência e Agrotecnologia, v.31, p.1035-1042, 2007.

MSTAT-C. A software program for the design, management and analysis of agronomic research experiments. East Lansing: Michigan State University, 1991. Irregular paging.

RAMALHO, M.A.P.; FERREIRA, D.F.; OLIVEIRA, A.C. de. Experimentação em genética e melhoramento de plantas. Lavras: UFLA, 2005. 300p.

RAMALHO, M.A.P.; SANTOS, J.B. dos; ZIMMERMANN, M.J. de O. Genética quantitativa em plantas autógamas: aplicações ao melhoramento do feijoeiro. Goiânia: UFG, 1993. 271p.

RESENDE, M.D.V. de. Matemática e estatística na análise de experimentos e no melhoramento genético. Colombo: Embrapa Florestas, 2007. 561p.

RESENDE, M.D.V. de; DUARTE, J.B. Precisão e controle de qualidade em experimentos de avaliação de cultivares. Pesquisa Agropecuária Tropical, v.37, p.182-194, 2007.

SILVA, V.M.P. e; RAMALHO, M.A.P.; ABREU, A. de F.B.; SILVA, F.B. Estimation of competition parameters in common bean plants. Crop Breeding and Applied Biotechnology, v.7, p.360-366, 2007.

VIEIRA, C.; BORÉM, A.; RAMALHO, M.A.P.; CARNEIRO, J.E. deS. Melhoramento do feijão. In: BORÉM,A.(Ed.). Melhoramento de espécies cultivadas. Viçosa: UFV, 2005 p.301-392.

Recebido em 8 de novembro de 2010 e aprovado em 10 de setembro de 2011 